\title{
BUSIER BEES: INCREASING NEST TRAFFIC IN COMMERCIAL BUMBLEBEE COLONIES
}

\author{
Callum D. Martina*, Callum Tonera, Michelle T. Fountain', Mark J. F. Browna \\ ${ }^{a}$ School of Biological Sciences, Royal Holloway University of London, Egham, Surrey, United Kingdom \\ ${ }^{b}$ NIAB EMR, East Malling Research, East Malling, Kent, United Kingdom
}

\begin{abstract}
Commercially-reared bumblebee colonies contribute to the pollination of crops globally. If the efficiency of commercial colonies at providing pollination services could be increased, it would have implications for agricultural outputs. Commercial colonies are sold with an internal nectar reservoir on which bees can forage from within the nest. Nectar stores in naturally-produced nectar pots of colonies can affect forager recruitment and activity outside the nest. Thus, it is possible that artificial nectar reservoirs could impact the foraging activity of colonies. To investigate this, commercial Bombus terrestris audax colonies were placed in a university parkland campus. Colonies were split into three treatment groups: those with (I) access to an unaltered nectar reservoir; (2) access to a diluted reservoir; and (3) no reservoir access. Foraging observations were made for all colonies over a I9-day period. The mass of each colony was measured and demographic data were collected. Colonies with diluted reservoirs had I3I\% and $39 \%$ more bees entering and leaving than colonies with no reservoir access and unaltered reservoirs respectively. Both treatments with access to a nectar reservoir gained more mass, had a higher proportion of pollen foraging bees, and had more workers, males, larvae and pupae, than colonies with no access to a reservoir. These results demonstrate that manipulating the availability and concentration of internal nectar reservoirs of commercial $B$. terrestris colonies significantly affects the number of bees entering and leaving the colony. Dilution of the nectar reservoir could be a strategy for increasing the pollination services commercial colonies provide to crops. Further research in commercial crops is required before such a strategy could be implemented on farms.
\end{abstract}

Keywords: colony activity, ecosystem service, nectar availability, nectar concentration, pollination, social insect

\section{INTRODUCTION}

Bees are one of the most important pollinator groups, contributing to global food production, and human health and wellbeing (Klein et al. 2007; Aizen et al. 2009; Kleijn et al. 2015; Rader et al. 2016). A significant proportion of crop pollination services are provided by populations of managed honey-bees and commercial bumblebees, which increase yield and quality of crops, and provide a buffer against the declines of many wild pollinator species (Klein et al. 2007; Calderone 2012; Klatt et al. 2014). Honeybees are the dominant managed pollinator globally, but commercially reared bumblebees are increasingly used as they are superior pollinators for certain crop types and environments (Willmer et al. 1994; Stanghellini et al. I998; Zhang et al. 2015).

Despite the widespread use of commercial bumblebees, little research has investigated how to optimise their pollination services. One obvious driver of pollination services is the number of bees that leave a colony to visit the crop. If the rate at which bees leave their colony to forage on the crop could be enhanced, the pollination services each colony provides to the crop could potentially be improved. In addition to enhancing crop productivity, this could reduce the

Received 22 June 2018, accepted I6 January 2019

${ }^{*}$ Corresponding author: Callum.Martin.20I4@live.rhul.ac.uk number of commercial colonies that are required in crops, meaning growers could save money purchasing fewer colonies, and reduce the negative impacts that commercial bumblebee colonies may have on wild bee populations (Inoue et al. 2008; Meeus et al. 20I I; Schmid-Hempel et al. 20I4).

One area of commercial colony design that could be altered to induce changes in foraging is the internal nectar reservoir. All commercial colonies are supplied with an internal nectar reservoir filled with an artificial nectar solution located underneath the plastic nest box containing the colony. If the cap of the nectar reservoir is removed (as is standard practice for colonies placed among crops), then bees can access nectar in the reservoir from inside the nest via a cotton wick (Biobest 2017). The reservoir was initially introduced to stop commercial bumblebees from starving, because they were used predominantly to pollinate tomato, whose flowers do not provide nectar (Velthuis \& van Doorn 2006). However, commercial bumblebees are increasingly being used on a variety of other crops, many of which do provide a source of floral nectar (Velthuis \& van Doorn 2006). On such crops, the utility of the commercial colony nectar reservoir is less obvious, although when colonies are placed outside, the reservoir may help to sustain them during periods of poor weather. However, such nectar reservoirs may also act to alter the foraging activity of bees, and thus their effectiveness as pollinators. If a source of high-quality nectar within the nest alters the motivation of bees to forage, this could affect the yield, quality and value of the crop. 
There are several possible mechanisms by which nectar reservoirs in commercial colonies could influence foraging activity. Given that the nectar reservoir is accessible at all times, it may be possible for colonies to keep all of their naturally-constructed wax nectar pots full, meaning that demand for nectar is low, which is likely to reduce the foraging activity of the colony (Cartar 1992; Pelletier \& McNeil 2004; Dornhaus \& Chittka 2005; Molet et al. 2008). However, if not all the nectar pots are full and demand for nectar is high, a sudden influx of nectar to the nectar pots from the nectar reservoir could stimulate more foragers to search for nectar (Dornhaus \& Chittka 200I, 2005). Thus, there are potential mechanisms by which the reservoir could both increase and decrease foraging activity of commercial bees.

Furthermore, the concentration of the nectar within the reservoir may also impact the number of foragers recruited from the colony. When a forager returns to the colony with nectar of a high sugar concentration, it is more likely to perform longer excitatory runs and spend more time running quickly around the nest (Dornhaus \& Chittka 2005; Nguyen $\&$ Nieh 2012). This activity, combined with the release of a pheromone, alerts nest mates of nectar resources (Dornhaus \& Chittka I999, 200I; Dornhaus et al. 2003), and doing it for a longer period, at a higher speed, and over a longer distance is thought to recruit a larger number of foragers (Dornhaus \& Chittka 2005; Nguyen \& Nieh 20I2). Indeed, studies have shown colony activity to increase more when bees return with high quality nectar compared to lower quality nectar (Dornhaus \& Chittka 2005; Nguyen \& Nieh 2012). In addition, if high and low quality nectar are injected directly into honeypots, then the high quality nectar stimulates more activity from the colony than the low quality nectar (Dornhaus \& Chittka 2005). This suggests that in order to maximise the number of foragers in a colony, higher quality nectar should be used in the reservoir, however it is not known how high quality nectar available directly in the nest will influence foraging outside the nest. It could be that foraging for high quality nectar from the reservoir only stimulates further foraging from the reservoir, rather than stimulating foraging outside the nest, and it is foraging outside the nest that is required for crop pollination.

Finally, both nectar and pollen are required by colonies, and their availability has been demonstrated to affect colony development (Cartar \& Dill I99I; Pelletier \& McNeil 2003). Thus, the presence and concentration of the nectar reservoir could also impact colony development. Access to the nectar reservoir may give workers of the colony more energy to enable pollen foraging bouts. In addition, the nectar reservoir may provide all the nectar that a colony requires, meaning that the colony is able to increase the proportion of foragers, and thus, collect more pollen. Both of these factors could subsequently allow the colony to raise more worker offspring and produce larger colonies with more foragers to pollinate a crop. In contrast, the opposite may be true for colonies with no access to a nectar reservoir.

It is clear that there are numerous possibilities for how the nectar reservoir could affect commercial bumblebee foraging activity, with different mechanisms acting in opposing directions. Here, we directly investigated the effects of altering the availability and concentration of the nectar reservoirs of commercial Bombus terrestris audax colonies on the number of bees entering and leaving colonies (hereafter referred to as 'nest traffic') and colony development.

\section{MATERIALS AND METHODS}

Twenty-one B. terrestris audax colonies were purchased from Biobest (Belgium). Upon arrival each colony was removed from its outer cardboard box, its mass was measured three times to generate a mean mass, and then it was returned to its box. Colonies were randomly assigned to one of three treatments (seven colonies in each treatment). In the control treatment, the caps were removed from the nectar reservoirs allowing bees access to the nectar, and the content of the reservoirs was left unaltered (remaining at $60 \% \mathrm{w} / \mathrm{w}$ sugar concentration), as would be the case for standard deployment of commercial colonies in a crop. The sugar water in Biobest nectar reservoirs consists primarily of fructose, glucose and sucrose with potassium sorbate and citric acid added as preservatives (Biobest personal communication, 2018). In the diluted treatment, half of the contents $(700 \mathrm{ml})$ of each nectar reservoir was removed and then replaced with the same amount of distilled water, to make a solution of $40 \% \mathrm{w} / \mathrm{w}$ sugar concentration. The diluted reservoir was shaken vigorously to ensure a fully mixed solution, and again the caps of the reservoirs were removed. In the final treatment, the nectar reservoirs were left unaltered and with their caps on, meaning bees could not access the contents of the reservoir. After the treatments had been applied, the sugar concentration of each reservoir was measured from a I $\mathrm{ml}$ sample using a hand-held refractometer (Bellingham \& Stanley), and the mass of each reservoir was measured three times so that consumption of the contents by the colonies could be estimated for the duration of the experiment. Reservoirs were then placed underneath their associated colonies, as recommended by the supplier.

On the same day, after treatments had been applied, colonies were placed into field boxes (details below) positioned in a clearing on the Royal Holloway University of London campus (latitude: 51.424643, longitude: 0.563490 ). The campus is a mix of florally rich borders, meadows, and woodland, surrounded by suburban areas containing gardens, habitats which are known to provide significant foraging resources for bumblebees (Baldock et al. 2015). The boxes were positioned in triplets around the clearing. Within a triplet, one colony from each of the three treatments were placed 3-6 metres apart from each other. Triplets were separated from other triplets by $10-20 \mathrm{~m}$. The boxes were positioned so the entrances to the colonies were all south facing. Field boxes were sturdy plastic boxes (W $67 \times$ L $127 \times$ D $50 \mathrm{~cm}$; Allied Plastics, Kingston, UK) lined with insulation and pegged to the ground. Lids to the boxes were held secure with a ratchet. The boxes protected colonies from the rain and disturbance by wildlife. The field boxes were connected to the colony boxes with a transparent plastic tube through which bees could enter and exit the colony. The end of the tube was wrapped in black tape to make it easier for returning bees to find the colony entrance. 


\section{Foraging observations}

A day after colonies were placed outside, foraging observations began. Nineteen days of foraging observations were carried out, from 2I July - 8 August 20I7, this was 45$34 \%$ of the 6-8-week time period that colonies are recommended to be used for in commercial crops. Seven colonies were observed each day between 09:00 and 12:30, so all 2I colonies were observed once over a 3-day period. Over the whole I9-day sampling period, each colony was observed 6 times.

To ensure that colonies from a given treatment were not all observed at a similar time of day, which could bias the results, colonies from each treatment group were observed one after the other, e.g. a colony from the control treatment would be observed, followed by a colony from the diluted treatment, followed by a colony from the undiluted treatment. The order of selection of each colony from its treatment group was done randomly.

Each colony observation period lasted 30 minutes. The observer positioned themselves so the nest entrance was visible, and every incidence of a bee entering or leaving the colony was recorded. It is possible that the same individual bee was counted more than once in a single observation, but since bees were not marked, we cannot quantify this. For returning bees it was also noted if the bee was carrying pollen in its corbiculae or not. Temperature was recorded at the start of each observation. If it was raining no observations were taken.

At the end of the 19-day observation period, all colonies were closed at nightfall, to ensure that most bees were inside their respective colonies. The colonies were then removed from field boxes and placed into a freezer at $-20^{\circ} \mathrm{C}$. The mass of each reservoir was measured three times and its sugar concentration measured to see if any changes in mass and concentration occurred during the trial.

\section{Colony demographics}

After the colonies had been freeze-killed, their masses were measured three times, and the numbers of workers, males, gynes (female reproductive offspring), larvae, and pupae were counted for each colony. Whether the founding queen was present was also noted.

\section{Statistical analyses}

All statistical analyses were performed using ' $R$ ' programming software version 3.5.I (R Core Team 2018).

\section{Nest traffic}

Nest traffic (the total number of bees entering and leaving the colony in each 30 minute observation window) was analysed using a negative binomial generalised linear mixed effect model (GLMM), using the R package 'glmmADMB' (Fournier et al. 2012; Skaug et al. 2016). The covariables included in the model were 'treatment' and 'temperature'. The random effects structure contained the 3-day sampling period that observations occurred in, and the colony identity nested within the triad of colonies.
To examine the differences between the treatment groups, post-hoc Tukey pairwise comparisons were performed using the package 'emmeans' (Lenth 2018). The same post-hoc test was applied to all the following models.

\section{Proportion of pollen foragers}

For each treatment, the proportion of returning bees that were carrying pollen loads was analysed. A zero-inflated binomial generalised linear mixed effects model (GLMM) was fitted with the package 'glmmADMB' (Fournier et al. 20I2; Skaug et al. 2016) to analyse this variable. The covariables and random effects structure were identical to those in the nest traffic model, and the same post-hoc analysis was performed.

\section{Colony and reservoir mass change}

The changes in mass of the colonies and nectar reservoirs that occurred during the I9-day observation period were calculated by subtracting their end mass from their start mass. The mass change variables were then analysed using generalised linear models (GLM). The response variable 'colony mass change' was Box-Cox transformed $(\lambda=0.2222)$ to meet the assumptions of the statistical method, and the covariables used were 'treatment' and 'colony starting mass'.

For the 'reservoir mass change' variable, no transformation was necessary, and the covariables used were 'treatment' and 'nest mass change'. Reservoir mass change was used as an approximation of how much reservoir nectar colonies had consumed.

\section{Number of workers, males, larvae and pupae}

The number of workers counted from the frozen colonies after the 19-day observation period was analysed using a generalised linear model (GLM) with a Poisson error structure. The response variable was Box-Cox transformed $(\lambda$ $=0.6666)$ to meet the assumptions of the statistical method. The covariables used in the model were 'treatment' and 'nest starting mass'.

The number of males, larvae and pupae were all analysed using negative binomial generalised linear mixed effects models (GLMM). All these models had 'treatment' and 'nest starting mass' as covariables and included 'colony identity' nested within 'triad' as a random effect.

Models that were fitted using the glmmADMB package were validated by visual inspection of plots of the residuals plotted against the fitted values, and QQ-plots. Normality of the residuals was also formally tested using Shapiro-Wilk tests. All other models were validated using functions within the 'DHARMa' package (Hartig 2018). Normality of residuals, dispersion and zero-inflation were all formally tested for using this package.

\section{Number of gynes}

The counts for gyne production were low, with many colonies not producing any at all, thus no statistical analyses were carried out on these data. 


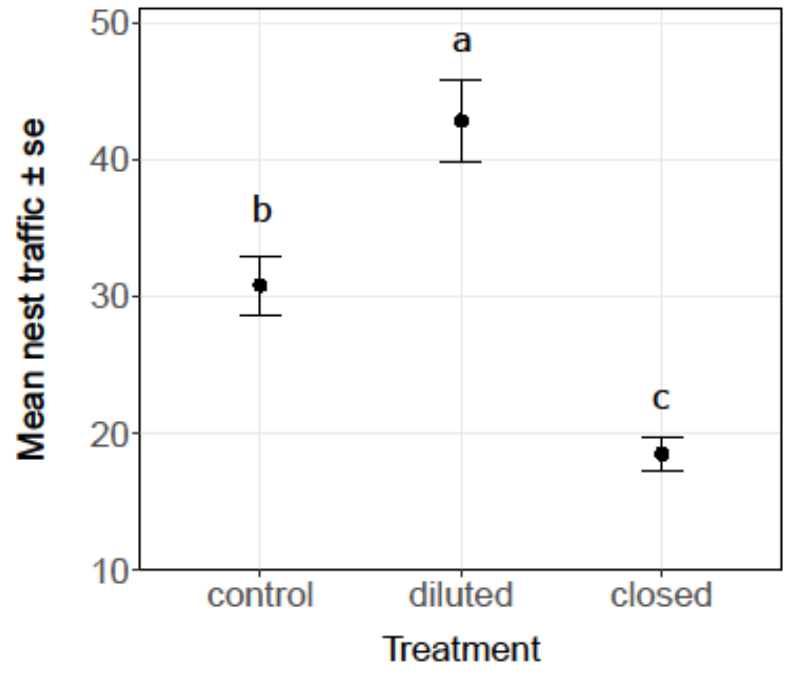

FIGURE I. Mean nest traffic (number of $B$. terrestris entering and leaving the colony) in the 30-minute colony observation periods for colonies within the three treatment groups. Circles indicate backtransformed least square means \pm standard error. Means sharing the same letter are not significantly different from each other at the .05 significance level. Control treatment colonies $(N=7)$ had an unaltered internal nectar reservoir (60\% sugar concentration), diluted treatment $(N=7)$ had a diluted reservoir $(40 \%$ sugar concentration), and the closed treatment $(N=7)$ had no access to an internal nectar reservoir.

\section{RESULTS}

Over the 19-day observation period each colony was observed 6 times; a total of 63 hours of colony observations.

\section{Nest traffic}

The diluted reservoir treatment had 39\% more nest traffic than the control colonies and $131 \%$ more than the closed reservoir colonies (GLMM: control: $Z=-4.45, P<0.05$; closed: $Z=7.58, P<0.05$; Fig I).

\section{Proportion of pollen foragers}

Colonies from the diluted treatment had a significantly higher proportion of pollen foragers than colonies from the closed reservoir treatment (GLMM: $Z=2.65, P<0.05$; Fig 2). Control colonies did not significantly differ in the proportion of pollen foragers compared to diluted and closed reservoir colony treatments (GLMM: diluted: $Z=-1.62, P>$ 0.05; closed: $Z=2.26, P>0.05)$.

\section{Colony and reservoir mass change}

Colonies from all treatments gained mass, however colonies from the closed reservoir treatment gained significantly less mass than the control and diluted colonies (GLM: control: $Z=5.72, P<0.05$; diluted: $Z=3.39, P<$ 0.05; Fig 3 ). The starting mass of each colony had a significant positive effect on the colony mass change (GLM: $T=2.7 \mathrm{I}, P<0.05)$

There was no effect of the diluted treatment on the nectar reservoir mass change (GLM: $T=-0.99, P=0.35$ ). Colonies that gained the most mass also had the greatest reduction in nectar reservoir mass (GLM: $T=2.24, P=0.047$ ).

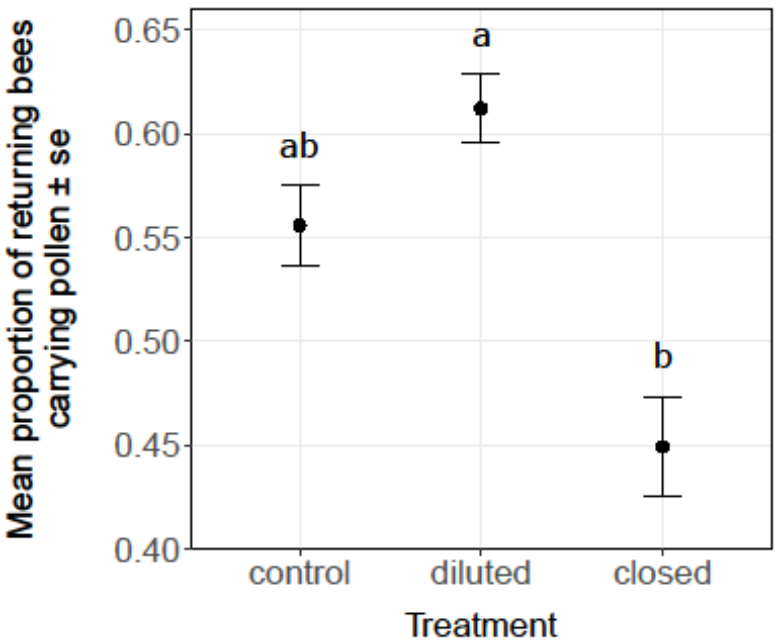

FIGURE 2. Mean proportion of $B$. terrestris returning to the colony with pollen from each treatment group in the 30-minute colony observation periods. Circles indicate back-transformed least square means \pm standard error. Means sharing the same letter are not significantly different from each other at the .05 significance level. Control treatment colonies $(N=7)$ had an unaltered internal nectar reservoir ( $60 \%$ sugar concentration), diluted treatment $(N=7)$ had a diluted reservoir ( $40 \%$ sugar concentration), and the closed treatment $(N=7)$ had no access to an internal nectar reservoir.

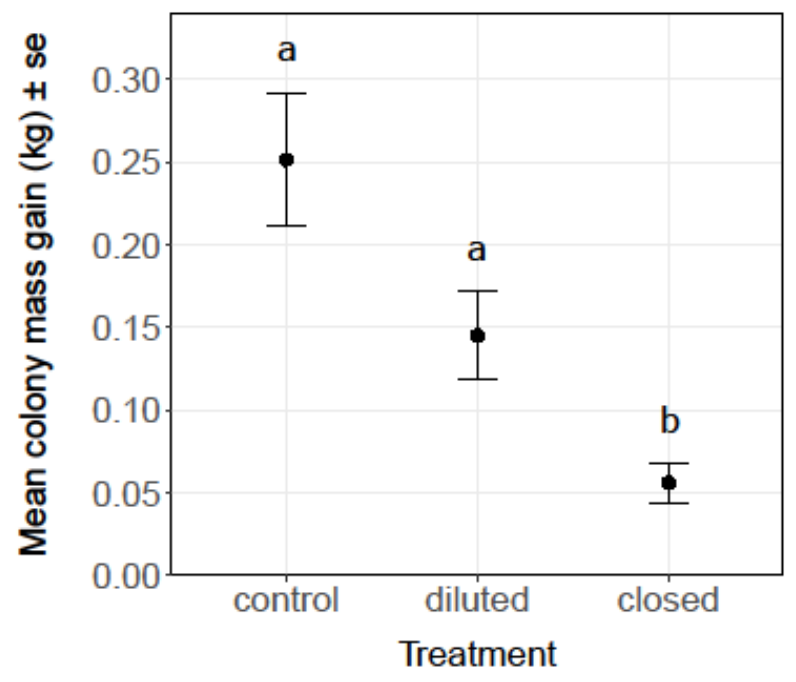

FIGURE 3. Mean mass gain of $B$. terrestris colonies from each treatment group. Circles indicate back-transformed least square means \pm standard error. Means sharing the same letter are not significantly different from each other at the .05 significance level. Control treatment colonies $(N=7)$ had an unaltered internal nectar reservoir ( $60 \%$ sugar concentration), diluted treatment $(N=7)$ had a diluted reservoir (40\% sugar concentration), and the closed treatment $(N=7)$ had no access to an internal nectar reservoir.

\section{Colony demographics}

Closed reservoir colonies had significantly fewer workers, males, pupae and larvae than control colonies (GLM: workers: $Z=8.74, P<0.05$; GLMM: males: $Z=5.3 \mathrm{I}, P<0.05$; pupae: $Z=7.70, P<0.05$; larvae: $Z=4.53, P<0.05$; Fig 4) and diluted colonies (GLM: workers: $Z=8.4 \mathrm{I}, P<0.05$; GLMM: males: $Z=3 . \mathrm{II}, P<0.05$; pupae: $Z=5 . \mathrm{II}, P<$ 

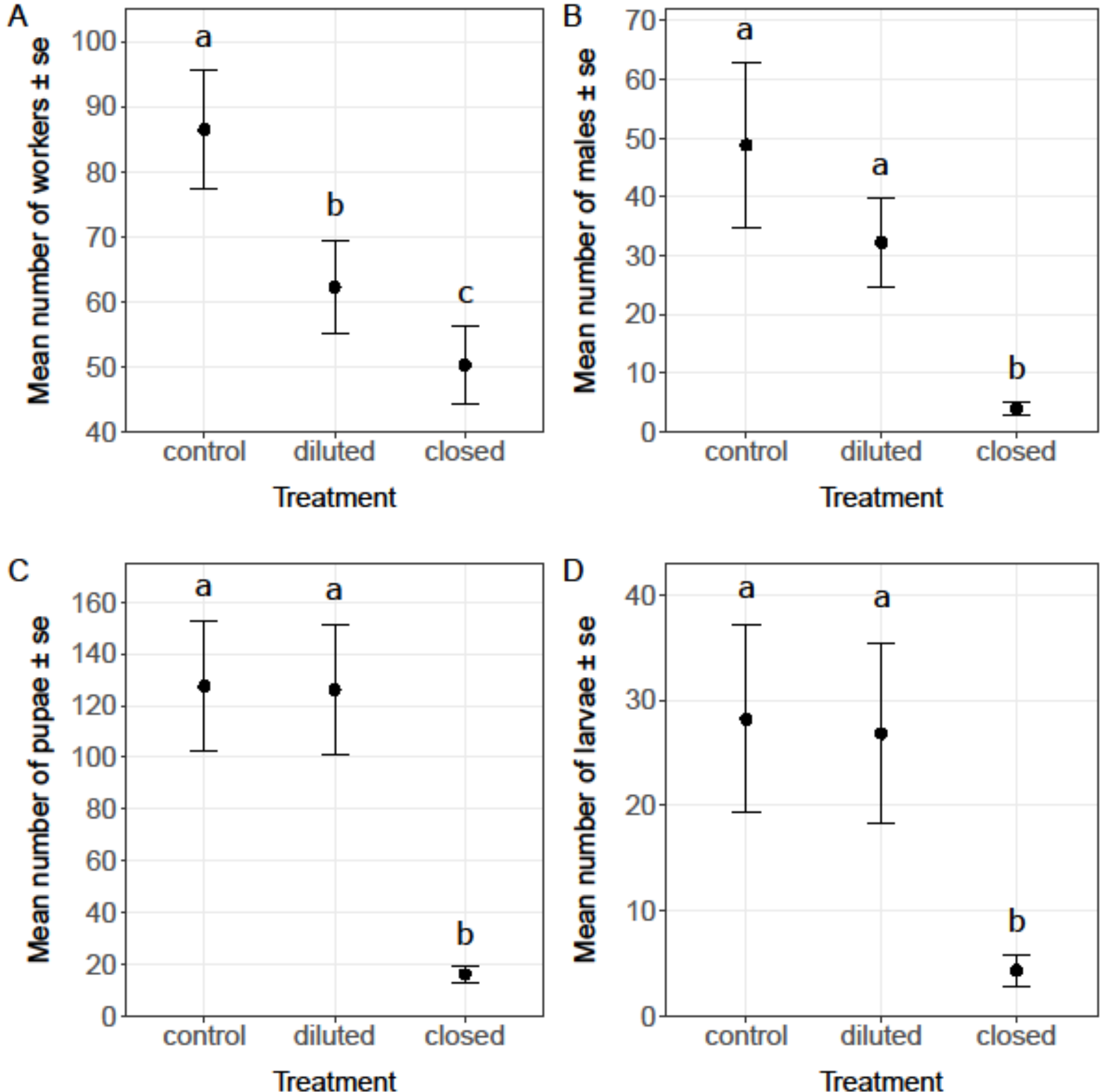

Figure 4. Mean number of B. terrestris (A) workers, (B) males, (C) pupae, and (D) larvae from each treatment group found in colonies after I9 days in the field. Circles indicate back-transformed least square means \pm standard error. Means sharing the same letter are not significantly different from each other at the .05 significance level. Control treatment colonies $(N=7)$ had an unaltered internal nectar reservoir $(60 \%$ sugar concentration), diluted treatment $(N=7)$ had a diluted reservoir ( $40 \%$ sugar concentration), and the closed treatment $(N=7)$ had no access to an internal nectar reservoir.

0.05; larvae: $Z=4.40, P<0.05$; Fig 4 ) after I9 days in the field. In addition, diluted reservoir colonies had significantly fewer workers than control colonies (GLM: $Z=8.80, P<$ $0.05)$. There were no other significant differences between the treatment groups.

\section{Number of gynes}

A mean $( \pm$ SE) of $0.43( \pm 0.20)$ gynes were found in control colonies, 6.I4 ( \pm 2.68) were found in diluted treatment colonies, and none were found in closed reservoir colonies.

\section{Nectar reservoir concentration}

The sugar concentrations of the nectar reservoirs were the same at the end of the experiment as they were at the beginning.

\section{DISCUSSION}

The results clearly demonstrate that manipulating both the availability and concentration of the internal nectar reservoirs of commercial B. terrestris audax colonies can significantly affect the number of bees entering and leaving the colony. Colonies with a diluted nectar reservoir had 39\% and 
I3I\% more nest traffic than control and closed reservoir colonies respectively. This suggests that there is potential for the pollination services provided by commercial bumblebees to be improved with such a dilution.

The higher levels of nest traffic observed from the diluted reservoir treatment colonies compared to the undiluted control treatment may have been caused by bumblebees' preference for higher concentration nectar (Cnaani et al. 2006; Bailes et al. 2018). Nectar of $40 \%$ sugar concentration, as in the nectar reservoirs of colonies from the diluted treatment, is of a higher concentration than the nectar provided by a range of floral resources (Wolff 2006; Fowler et al. 2016), but it is still possible to find higher concentration nectar in the natural environment (Chalcoff et al. 2006). In contrast, it is unlikely that there will be nectar in the environment with a higher concentration than 60\% (Chalcoff et al. 2006; Knopper et al. 2016; Fowler et al. 2016). In addition, nectar with sugar concentrations of over $60 \%$ starts to become highly viscous which slows down the rate at which bumblebees can imbibe it, thus slowing the rate of energy intake and potentially making it a less attractive nectar source (Nardone et al. 2013; Bailes et al. 2018). Given that bumblebee foraging behaviour must have evolved against a background of natural diversity in nectar concentrations, it is possible that bumblebees from the diluted treatment had more motivation to forage outside the nest than bees from the undiluted treatment. Furthermore, the nectar reservoirs from the control treatment lost on average more mass than those from the diluted treatment, though not significantly so, adding further evidence that the commercial bumblebees preferred the $60 \%$ over the $40 \%$ sugar concentration nectar. In addition, both treatments with access to a reservoir had more workers, males, larvae and pupae than closed reservoir colonies. Such increases will have further increased the nectar demand of the colonies. However, diluted colonies could not gain as much nutrition from their reservoirs as undiluted colonies, and so had to forage more, potentially outside of the nest to acquire nectar of higher sugar concentration.

If the potential for better quality foraging resources outside the nest was the only factor influencing the activity of the colonies, then we would expect the closed reservoir treatment to show the highest activity levels, but this was not the case. The control and diluted treatment (i.e. the colonies with access to nectar) both had significantly higher nest traffic counts than the closed reservoir treatment. Here, we hypothesise some possible mechanisms that may lie behind this result. Firstly, both treatments with access to nectar gained significantly more mass and contained more workers at the end of the 19-day sampling period than the colonies without access. This suggests that these colonies grew to a larger size, and thus were able to recruit more foragers, resulting in the elevated levels of nest traffic. Nectar and pollen are critical in the development of a bumblebee colony (Sladen I912), and colonies with access to nectar also had a significantly higher proportion of pollen foragers, which is likely to have helped enable their growth. This increased pollen foraging may itself have been enabled by the nectar reservoir giving bees more energy to forage more frequently and for longer periods of time, and by providing them with a source of nectar with which to form corbicular pollen loads. In addition, higher numbers of males, gynes and pupae were recorded in colonies with access to a reservoir, suggesting that these colonies were better able to maintain the eggs and larvae that were present when the colonies were placed in the field. Higher larvae numbers were also observed from these colonies, indicating that they had enhanced levels of development. This is in agreement with literature showing the importance of nectar and pollen for colony development, size, and reproductive success (Cartar \& Dill I99I; Pelletier \& McNeil 2003).

Secondly, bees from the closed reservoir treatment may have lacked energy to perform regular and long foraging trips, reducing the chances of their foraging trips being successful. Even colonies with a high demand for nectar have low activity levels unless foragers are returning and providing a nectar influx into the nest (Dornhaus \& Chittka 2005). It has been suggested that this could be a strategy for energy conservation, so foraging trips are only initiated if they have a high chance of being successful (Dornhaus \& Chittka 2005), and it is likely to have contributed to closed reservoir treatment colonies having much reduced nest traffic.

A final possible mechanism is that in the colonies that had nectar reservoir access, regular influxes of nectar from the nectar reservoir could have stimulated foraging (Dornhaus $\&$ Chittka 2005). Since bumblebees do not communicate the location of forage resources to other nest mates, the stimulated foraging may have occurred outside the nest, rather than on the nectar reservoir, resulting in more nest traffic. However, we believe that this mechanism is unlikely, as returning foragers do communicate the odour of foraging resources (Dornhaus \& Chittka 1999). Thus, it is possible that this mechanism could have resulted in more foraging from the reservoir.

The results we present seemingly contrast with other similar studies from the literature (Cartar 1992; Pelletier \& McNeil 2004). Cartar (1992) found that depletion of nectar stores from bumblebee colonies increased nest traffic, however, the depletion was immediate and nest traffic was monitored for 1.5 hours very shortly after the depletion. If the colony had remained in a nectar depleted state for a longer period (I-2 days), nest traffic might have decreased to much lower levels similar to those seen in the depletion treatment in Dornhaus and Chittka (2005) and in the closed reservoir treatment in this experiment. In a longer-term study, Pelletier \& McNeil (2004) found that bumblebee colonies provided with ad libitum nectar and supplementary pollen within the nest foraged less than those that were not supplemented. In their study, foraging observations only began one month after the nutritional manipulations were implemented, meaning there was no overlap with the time period of our study. It is possible that we might have seen an increase in nest traffic from the closed reservoir colonies had we left them in the field for a longer time. However, we think this is very unlikely given that these colonies had significantly lower numbers of workers, pupae and larvae than colonies with access to a nectar reservoir, and so would be unable to greatly increase their foraging workforce. We believe the habitat the colonies were placed in may have been more nectar rich in the Pelletier \& McNeil (2004) study compared to our study, thus allowing non-supplemented colonies to forage and develop well. 
A factor that could have affected our results is nectar robbing between colonies, especially given the proximity of colonies to each other. For example, colonies from the diluted reservoir treatment may have robbed colonies from the undiluted control treatment for their higher quality nectar, resulting in more nest traffic from the diluted reservoir colonies. In response to this, more bees from the undiluted control colonies may have remained in the nest to defend against robbers. Such an effect could explain the differences observed in nest traffic between diluted and undiluted reservoir colonies. However, although drifting between bumblebee colonies is known to occur (Birmingham \& Winston 2004; Zanette et al. 20I4), it is not known how much of this drifting is for nectar robbing purposes. Thus, we do not know the magnitude of the effect that robbing may have had on our results. Quantification of nectar robbing would be something to consider in future experiments.

The results presented here suggest that diluting nectar reservoirs of commercial B. terrestris audax colonies can increase the number of foragers, which could subsequently improve the pollination services provided to a crop. However, a potential disadvantage to diluting the nectar reservoir could be a reduction in longevity of the nectar, as microorganisms are better able to survive at lower sugar concentrations. In this experiment, no fungal growths were observed with the naked eye in any of the nectar reservoirs after 19 days in the field. However, suppliers recommend that commercial colonies be left out in the target crop for 6-8 weeks (approximately 2-3 times the length of our experiment). After this length of time, it is possible that the reservoirs could be contaminated with fungus, in which case such contamination is likely to be more severe in diluted reservoirs with a lower sugar concentration. It is possible that contamination of the reservoir may cause bees to become averse to this nectar source, and bees feeding from it may suffer negative health consequences leading to a possible reduction in the size of the colony, its foraging activity, and subsequently the pollination services it is providing. However, nectar contaminated with yeast has been shown to be preferentially selected by bumblebees over noncontaminated nectar (Herrera et al. 2013; Schaeffer et al. 2017), and no detrimental fitness effects have been detected. The preferential selection of yeast contaminated nectar may even suggest a positive fitness effect of yeast containing nectar, but this has not been demonstrated. What effect microorganism growth in commercial colony nectar reservoirs may have on commercial colonies remains to be tested, but it is potentially a complex issue.

Whilst this study clearly demonstrates that manipulations of the nectar reservoir of commercial B. terrestris audax can significantly alter nest traffic, further research is required to investigate what effect these alterations might have on the pollination of crops. An obvious follow-up to this study would be to apply nectar reservoir dilution treatments to commercial bumblebee colonies in different cropping systems. This would clarify whether the trends observed here are replicated in a very different foraging environment, and if they are, whether higher nest traffic does translate into better pollination services, crop quality and yield. Effects of dilution could vary in different crops depending on the volume and sugar concentration of the nectar that they produce. For example, tomato crops produce no nectar and can be grown in closed glasshouses from which bees may not be able to escape, thus, the nectar reservoir is their only source of nectar. In this case, dilution of the reservoir would be reducing the total sugar content of the only available nectar source, which could negatively affect the development of the colony. However, several other crop types for which commercial bumblebees are used do produce nectar. It is on such crops that we would recommend testing the effect of reservoir dilution on colony nest traffic and crop pollination. In addition, the spatial arrangement of cropping systems is likely to affect the accessibility of alternate foraging resources in the surrounding landscape to the commercial bumblebees, which could also be a factor in the effect that nectar reservoir dilution has on commercial colonies.

Another factor that should be considered in future experiments is how the effect of the treatments we applied to colonies might vary over longer time periods than three weeks. It seems likely that over a longer duration the effects that the treatments have on colony demographics and development may play a greater role in determining the amount of foraging activity. For example, colonies that have more larvae and pupae at 3-weeks, are likely to have more of workers at 6 weeks, as the larvae and pupae have developed and emerged as adults. In this experiment, diluted and undiluted reservoirs had similar numbers of pupae and larvae, and significantly more pupae and larvae than closed reservoir treatments, suggesting that the trends seen in this study may have continued. However, a study conducted over the recommended pollination lifespan of commercial colonies of 6-8 weeks would be required to fully test whether the effect of the treatments changes temporally.

The results of this study could have applied value to the field of bumblebee research itself. Commercial colonies are regularly used for research purposes, and experimenters may wish to maximise nest traffic from colonies to allow greater volumes of data to be collected. Here, we demonstrate a method of increasing such nest traffic. Furthermore, studies investigating aspects of commercial colony development and reproduction will want to consider what impact use of the internal nectar reservoir may have on their results.

As it stands, this study shows that there is potential for the foraging activity of commercial bumblebee colonies to be significantly increased with a simple manipulation. If this trend can be replicated across different crop types in agricultural settings, then pollination efficiency may increase, and fewer colonies may be required to meet pollination demands, making farming more cost efficient and reducing the potential for environmental damage caused by commercial bumblebee colonies (Inoue et al. 2008; Meeus et al. 20II; Schmid-Hempel et al. 20I4).

\section{ACKNOWLEDGEMENTS}

We would like to thank Judit Bagi and Harry Siviter for advice and assistance with the experiment, and two anonymous reviewers for their useful comments which improved the manuscript. This study was funded by a BBSRC CASE studentship BB/LOI600I/I to M.J.F.B in collaboration with NIAB EMR and Berry Gardens. 


\section{REFERENCES}

Aizen MA, Garibaldi LA, Cunningham SA, Klein AM (2009) How much does agriculture depend on pollinators? Lessons from longterm trends in crop production. Annals of Botany I03:I579-88.

Bailes EJ, Pattrick JG, Glover BJ (2018) An analysis of the energetic reward offered by field bean (Vicia faba) flowers: Nectar, pollen, and operative force. Ecology and Evolution 8:3I6I-3I7I.

Baldock KCR, Goddard MA, Hicks DM, Kunin WE, Mitschunas N, Osgathorpe LM, Potts SG, Robertson KM, Scott A V, Stone GN, Vaughan IP, Memmott J (2015) Where is the UK's pollinator biodiversity? The importance of urban areas for flowervisiting insects. Proceedings of the Royal Society B-Biological Sciences 282:20142849.

Biobest (2017) Guidelines for the use of Biobest bumblebee hives ( $B$. terrestris).

Birmingham AL, Winston ML (2004) Orientation and drifting behaviour of bumblebees (Hymenoptera: Apidae) in commercial tomato greenhouses. Canadian Journal of Zoology 82:52-59.

Calderone NW (2012) Insect pollinated crops, insect pollinators and US agriculture: trend analysis of aggregate data for the period 1992-2009. PLoS ONE 7:e37235.

Cartar R V. (I992) Adjustment of foraging effort and task switching in energy-manipulated wild bumblebee colonies. Animal Behaviour 44:75-87.

Cartar R V., Dill LM (I99I) Costs of energy shortfall for bumble bee colonies: predation, social parasitism, and brood development. The Canadian Entomologist 123:283-293.

Chalcoff VR, Aizen MA, Galetto L (2006) Nectar concentration and composition of 26 species from the temperate forest of South America. Annals of Botany 97:4I3-2I.

Cnaani J, Thomson JD, Papaj DR (2006) Flower choice and learning in foraging bumblebees: effects of variation in nectar volume and concentration. Ethology I 12:278-285.

Dornhaus A, Brockmann A, Chittka L (2003) Bumble bees alert to food with pheromone from tergal gland. Journal of Comparative Physiology A I89:47-5I.

Dornhaus A, Chittka L (I999) Insect behaviour: evolutionary origins of bee dances. Nature 40I:38-38.

Dornhaus A, Chittka L (200I) Food alert in bumblebees (Bombus terrestris): possible mechanisms and evolutionary implications. Behavioral Ecology and Sociobiology 50:570-576.

Dornhaus A, Chittka L (2005) Bumble bees (Bombus terrestris) store both food and information in honeypots. Behavioral Ecology I6:66I-666.

Fournier DA, Skaug HJ, Ancheta JD, Ianelli J, Magnusson A, Maunder M, Nielsen A, Sibert J (2012) AD Model Builder: using automatic differentiation for statistical inference of highly parameterized complex nonlinear models. Optimization Methods and Software 27:233-249.

Fowler RE, Rotheray EL, Goulson D (2016) Floral abundance and resource quality influence pollinator choice. Insect Conservation and Diversity 9:48I-494.

Hartig F (2018) DHARMa: residual diagnostics for hierarchical (multi-level/mixed) regression models. $\mathrm{R}$ package version 0.2.0. https://CRAN.R-project.org/package=DHARMa.

Herrera CM, Pozo MI, Medrano M (2013) Yeasts in nectar of an early-blooming herb: sought by bumble bees, detrimental to plant fecundity. Ecology 94:273-279.

Inoue MN, Yokoyama J, Washitani I (2008) Displacement of Japanese native bumblebees by the recently introduced
Bombus terrestris (L.) (Hymenoptera: Apidae). Journal of Insect Conservation I2:135-I46.

Klatt BK, Holzschuh A, Westphal C, Clough Y, Smit I, Pawelzik E, Tscharntke T (20I4) Bee pollination improves crop quality, shelf life and commercial value. Proceedings of the Royal Society BBiological Sciences $28 \mathrm{I}$

Kleijn D, Winfree R, Bartomeus I, Carvalheiro LG, Henry M, Isaacs R, Klein A-M, Kremen C, M'Gonigle LK, Rader R, Ricketts TH, Williams NM, Lee Adamson N, Ascher JS, Báldi A, Batáry P, Benjamin F, Biesmeijer JC, Blitzer EJ, Bommarco R, Brand MR, Bretagnolle V, Button L, Cariveau DP, Chifflet R, Colville JF, Danforth BN, Elle E, Garratt MPD, Herzog F, Holzschuh A, Howlett BG, Jauker F, Jha S, Knop E, Krewenka KM, Le Féon V, Mandelik Y, May EA, Park MG, Pisanty G, Reemer M, Riedinger V, Rollin O, Rundlöf M, Sardiñas HS, Scheper J, Sciligo AR, Smith HG, Steffan-Dewenter I, Thorp R, Tscharntke T, Verhulst J, Viana BF, Vaissière BE, Veldtman R, Ward KL, Westphal C, Potts SG (2015) Delivery of crop pollination services is an insufficient argument for wild pollinator conservation. Nature Communications 6:74I4

Klein A-M, Vaissière BE, Cane JH, Steffan-Dewenter I, Cunningham SA, Kremen C, Tscharntke T (2007) Importance of pollinators in changing landscapes for world crops. Proceedings of the Royal Society B-Biological Sciences 274:303-I3.

Knopper LD, Dan T, Reisig DD, Johnson JD, Bowers LM (2016) Sugar concentration in nectar: a quantitative metric of crop attractiveness for refined pollinator risk assessments. Pest Management Science 72:1807-I2.

Lenth R (2018) emmeans: estimated marginal means, aka leastsquares means. $\mathrm{R}$ package version I.2.4. https://CRAN.Rproject.org/package $=$ emmeans.

Meeus I, Brown MJF, De Graaf DC, Smagghe G (20II) Effects of invasive parasites on bumble bee declines. Conservation Biology 25:662-67I.

Molet M, Chittka L, Stelzer RJ, Streit S, Raine NE (2008) Colony nutritional status modulates worker responses to foraging recruitment pheromone in the bumblebee Bombus terrestris Behavioral Ecology and Sociobiology 62:1919-1926.

Nardone E, Dey T, Kevan PG (2013) The effect of sugar solution type, sugar concentration and viscosity on the imbibition and energy intake rate of bumblebees. Journal of Insect Physiology 59:919-933.

Nguyen H, Nieh JC (2012) Colony and individual forager responses to food quality in the new world bumble bee, Bombus occidentalis. Journal of Insect Behavior 25:60-69.

Pelletier L, McNeil JN (2003) The effect of food supplementation on reproductive success in bumblebee field colonies. Oikos 103:688-694.

Pelletier L, McNeil JN (2004) Do bumblebees always forage as much as they could? Insectes Sociaux 5I:27I-274.

R Core Team (2018) R: a language and environment for statistical computing. R Foundation for Statistical Computing, Vienna, Austria.

Rader R, Bartomeus I, Garibaldi LA, Garratt MPD, Howlett BG, Winfree R, Cunningham SA, Mayfield MM, Arthur AD, Andersson GKS, Bommarco R, Brittain C, Carvalheiro LG, Chacoff NP, Entling MH, Foully B, Freitas BM, Gemmill-Herren B, Ghazoul J, Griffin SR, Gross CL, Herbertsson L, Herzog F, Hipólito J, Jaggar S, Jauker F, Klein A-M, Kleijn D, Krishnan S, Lemos CQ, Lindström SAM, Mandelik Y, Monteiro VM, Nelson W, Nilsson L, Pattemore DE, Pereira N de O, Pisanty G, Potts SG, Reemer M, Rundlöf M, Sheffield CS, Scheper J, Schüepp C, Smith HG, Stanley DA, Stout JC, Szentgyörgyi H, Taki H, Vergara CH, Viana BF, Woyciechowski M (2016) Non-bee 
insects are important contributors to global crop pollination. Proceedings of the National Academy of Sciences of the United States of America II3:146-5I.

Schaeffer RN, Mei YZ, Andicoechea J, Manson JS, Irwin RE (2017) Consequences of a nectar yeast for pollinator preference and performance. Functional Ecology 3I:613-62I.

Schmid-Hempel R, Eckhardt M, Goulson D, Heinzmann D, Lange C, Plischuk S, Escudero LR, Salathe R, Scriven JJ, Schmid-Hempel P (2014) The invasion of southern South America by imported bumblebees and associated parasites. Journal of Animal Ecology 83:823-837.

Skaug H, Fournier D, Bolker B, Magnusson A, Nielson A (2016) Generalized linear mixed models using 'AD model. R package version 0.8.3.3.

Sladen FWL (1912) The humble-bee: its life-history and how to domesticate it, with descriptions of all the British species of Bombus and Psithyrus.

Stanghellini M, Ambrose J, Schultheis J (1998) Seed production in watermelon: a comparison between two commercially available pollinators. HortScience 33:28-30.
Velthuis HHW, van Doorn A (2006) A century of advances in bumblebee domestication and the economic and environmental aspects of its commercialization for pollination. Apidologie 37:42I-45I.

Willmer PG, Bataw AAM, Hughes JP (1994) The superiority of bumblebees to honeybees as pollinators: insect visits to raspberry flowers. Ecological Entomology 19:27I-284.

Wolff D (2006) Nectar sugar composition and volumes of 47 species of gentianales from a southern Ecuadorian montane forest. Annals of Botany 97:767-777.

Zanette LRS, Miller SDL, Faria CMA, Lopez-Vaamonde C, Bourke AFG (20I4) Bumble bee workers drift to conspecific nests at field scales. Ecological Entomology 39:347-354.

Zhang H, Huang J, Williams PH, Vaissière BE, Zhou Z, Gai Q, Dong J, An J (2015) Managed bumblebees outperform honeybees in increasing peach fruit set in China: different limiting processes with different pollinators. PLOS ONE I0:eOI2II43. 